\title{
ANTIOXIDANT STATUS OF CALVES AND FOALS DECLINES AFTER BIRTH
}

\author{
M. Stohrer, Siglinde Lutz, M. Stangassinger
}

Institute of physiology, physiological chemistry and animal nutrition, LMU Munich, Veterinärstrasse 13, 80539 Munich, stohrer@tiph.vetmed.uni-muenchen.de

Antioxidant status is known to be a significant predictor of disease and mortality in infants, especially premature infants. It is unknown whether health of newborn animals is influenced by impairment of their antioxidant status. In order to characterize antioxidant status of calves and foals, trolox equivalent antioxidant capacity (TEAC) was measured in blood of cows and calves, as well as mares and foals, starting immediately after birth and continued over several weeks. Measurements of selected antioxidants should provide insight in their specific function and additional biochemical parameters should explain the causes for impairment of antioxidant status.

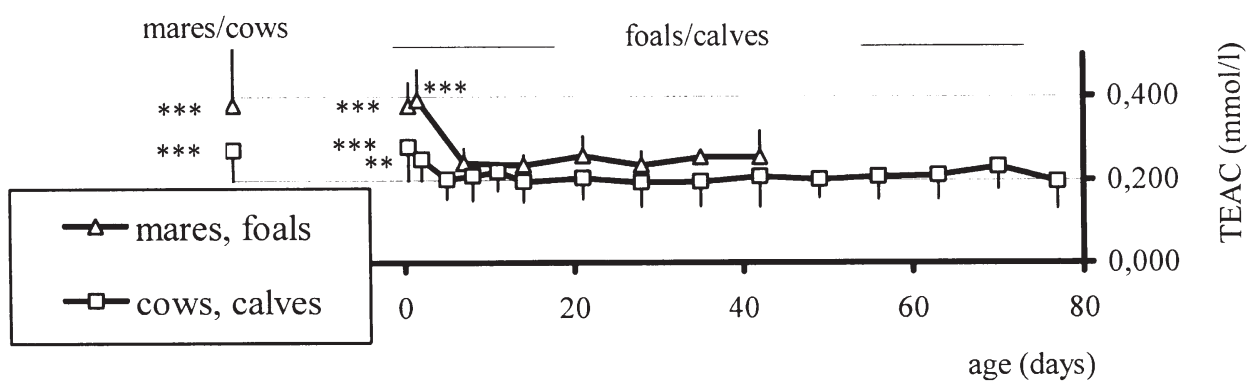

$* * * \mathrm{p}<0,001, * * \mathrm{p}<0,01$ significantly different to postnatal TEAC

TEAC levels were practically equal in blood sera of mares $(0.38 \pm 0.15 \mathrm{mmol} / \mathrm{l}, \mathrm{n}=67)$ and newborn foals $(0.38 \pm 0.06 \mathrm{mmol} / \mathrm{l}, \mathrm{n}=35)$. However, antioxidant status was significantly impaired during the first week of life $(0.24 \pm 0.03 \mathrm{mmol} / \mathrm{l}, \mathrm{n}=18$ at 7 th day $)$ and remained at low levels during the investigated period. The same pattern was found in cows $(0.27 \pm 0.07 \mathrm{mmol} / \mathrm{l}, \mathrm{n}=19)$, newborn calves $(0.28 \pm 0.08 \mathrm{mmol} / \mathrm{l}, \mathrm{n}=19)$ and calves after one week $(0.20 \pm 0.05 \mathrm{mmol} / \mathrm{l}, \mathrm{n}=19$ at 5 th day $)$

The postnatal TEAC decrease could be caused by ischemia/reperfusion injury during birth, reflected by a postnatal lactate rise to $4.81 \pm 2.14 \mathrm{mmol} / 1$ in foals or to $9.75 \pm 6.00 \mathrm{mmol} / 1$ in calves, respectively. Antioxidant consumption could also be due to (during degradation of fetal hemoglobin liberated) prooxidant $\mathrm{Fe}^{2+}$, raised to $64.83 \pm 12.61 \mu \mathrm{mol} / \mathrm{l}$ in foals, 1 st day, or $34.40 \pm 17.77 \mu \mathrm{mol} / \mathrm{l}$ in calves, 8th day. Improvement of the antioxidant status, e.g. by supplementing with vitamin E, could be beneficial in preventing oxygen radical induced diseases (e.g. white muscle disease).

\section{Literature}

Kelly, F.J. Free radical disorders of preterm infants. Brit. Med. Bull., Vol. 49(3): 668 - 678, 1993

Loudenslager, M. J., Ku, P.K., Whetter, P.A., Ullrey, D.E., Whitehair, C.K., Stowe, H.D., Miller, E.R. Importance of diet of dam and colostrum to the biological antioxidant status and parenteral iron tolerance to the pig. J. Anim.Sci., 63, 1905 - 1914, 1986 